\title{
TRTaKadeмi
}

ISSN 2149-9446 | Cilt 06 | Sayı 13 | Eylül 2021 | Yapay Zekâ

\section{Makine Merkezli Kamu Diplomasisinde Etik ve Etki Sorunsalı}

\section{Abdulsamet GÜNEK*}

\begin{abstract}
Öz
Uygulayıcısı ve hedef kitlesi insan olan kamu diplomasisi faaliyetleri makine merkezli bir sisteme dönüşmüştür. Makine merkezli kamu diplomasisinin temel odak noktası yapay zekâ teknolojisine dayanmaktadır. Diğer bütün alanlardaki uygulamalarında olduğu gibi kamu diplomasisi faaliyetlerinde de yapay zekânın kullanımı, etki ve etik tartışmasını içermektedir. Literatür analizine yönelik akademik çalışmalar; kamu diplomasisi alanıyla ilgili çalışmaların kavram, kurum, aktör ve eylem temelli analizlere odaklandığını göstermektedir. Bu makalede kamu diplomasisi faaliyetlerinde yapay zekâ kullanımı, etik ve etki sorunsalı çerçevesinde analiz edilmiştir. Kamu diplomasisi literatürü insani etki ve iletişim çerçevesinde sınıflandırılmıştır. Bu sınıflandırma sonucunda insan faktörünün ve etkisinin azaldığı makine merkezli kamu diplomasisi etki ve etik bağlamında analiz edilmiştir. Analiz yapay zekâ tartışmalarının merkezinde yer alan "kontrol", "denetim", "güvenlik" ve "etik çerçeve" ile kamu diplomasisi eylemlerinin tartş̧ma konusu olan "eylemin etkisi" bağlamı çerçevesinde oluşturulmuştur. Araştırma sonucunda makine merkezli kamu diplomasisinde yapay zekâ kullanımının hukuki ve fikri alt yapı eksikliği, denetim ve kontrol ikilemi, internet ve bilgiye erişimde bilgi açığı oluşturma, kaynak ve hedef kitlenin belirsizleşmesi, teknolojik belirlenimcilik gibi konularda çeşitli eksiklikler ve sorunlar içerdiği görülmektedir.
\end{abstract}

Anahtar Kelimeler: Kamu Diplomasisi, İnsan Makine Etkileşimi, Yapay Zekâ, Yeni Kamu Diplomasisi, Makine Merkezli Kamu Diplomasisi

*Dr. Öğr. Üyesi, Muş Alparslan Üniversitesi, İletişim Fakültesi, Gazetecilik Bölümü, sgunek@gmail.com

Günek, A. (2021). Makine Merkezli Kamu Diplomasisinde Etik ve Etki Sorunsalı . TRT Akademi , 6 (13) , $768-787$. DOI: $10.37679 /$ trta.969905

\section{Derleme Makale}

Geliş Tarihi: 11.07.2021

Kabul Tarihi: 13.09.2021 


\title{
TRTakadeMi
}

ISSN 2149-9446 | Volume 06 | Issue 13 | September 2021 | Artificial Intelligence

\section{Ethical and Impact Issues in Machine-Centered Public Diplomacy}

\author{
Abdulsamet GÜNEK
}

\begin{abstract}
Public diplomacy activities, whose practitioner and target audience are human, have turned into a machine-centered system. The main focus of machine-centered public diplomacy is based on artificial intelligence technology. The use of artificial intelligence in public diplomacy activities, as in other fields, includes the discussion of impact and ethics. Literature reviews show that studies in the field of public diplomacy mostly analyze concepts, institutions, actors and actions. In this article, the use of artificial intelligence in public diplomacy activities are analyzed within the framework of ethical and impact problematic. Public diplomacy literature has been classified in the context of human communication. The analysis is shaped on two pillars. first, the "control", "audit", "security", and "ethical context" that is at the center of the Al discussions. second, in the context of the "effect of action", which is the subject of debate in public diplomacy studies. As a result of the research, it is seen that the use of artificial intelligence in public diplomacy actions includes problems such as lack of legal and intellectual infrastructure, audit and control dilemma. Another result is the uncertainty of the source and target audience, and the emergence of the problem of technological determinism.
\end{abstract}

Keywords: Public Diplomacy, Human Machine Interaction, Artificial Intelligence, New Public Diplomacy, Machine-Centered Public Diplomacy 


\section{Giriş}

Kamu diplomasisi en genel tanımıyla bir ülkenin çeşitli araçlar kullanarak başka ülkelerin kamuoyunu kendi ülke çıkarları açısından etkileme girişimlerinin tümüne verilen eylemler bütünüdür. Kamu diplomasisine yönelik çalışmalar soğuk savaş boyunca genellikle propaganda yaklaşımı çerçevesinde şekillenmiştir. Ancak son dönem çalışmaları ${ }^{1}$ propaganda yaklaşımından farklı olarak kamu diplomasisini küreselleşme, yeni siyasal koşullar, teknolojik dönüşüme dayalı olarak çok boyutlu ve iki yönlü bir iletişim türü olarak tanımlamıştır.

Soğuk Savaştan günümüze kamu diplomasinin kurumları, eylemleri ve araçları çeşitlenerek derinleşmiştir. Kamu diplomasisi faaliyetleri klasik diplomasi faaliyetlerinin ülke çıkarını korumak ve sürdürmek açısından yetersiz olduğu varsayımı üzerinden derinleşmiş ve çeşitlenmiştir. Birinci Dünya Savaşı sırasında ülke kamuoylarını etkilemenin ve ülkelerin kamuoylarıyla etkileşime geçmenin önemi anlaşılmıştır. Ülkelerin ulusal sınırlarının ötesinde imajlarının yüceltilmesine yönelik anlayış ortaya çıkmıştır (Mellisen, 2005, s. 4). Bu bağlamda Amerika Birleşik Devletleri'nde ve Avrupa ülkelerinde çeşitli kurum ve kuruluşlar oluşturulmuştur. İkinci Dünya Savaşı'nda Hitler Almanya'sı yoğun bir şekilde kara propaganda tekniklerini kullanmıştır. Bu yıllarda savaş enformasyonu ve uluslararası yayıncılık faaliyetlerinin önemi anlaşılmıştır. ABD'de Amerika'nın Sesi Radyosu (1942), İngiltere'de BBC (1922) gibi kamu temelli yayın kuruluşları faaliyetlerini çeşitlendirmiş ve derinleştirmiştir.

Enformasyon ve uluslararası yayıncılık faaliyetlerinin yanı sıra kamu diplomasisinin eğitim, kültür, insani yardım, turizm ve ticaret gibi çeşitli boyutları bulunmaktadır. Kamu diplomasisi klasik diplomasinin sadece resmî ilişkiler üzerinden yürüyen formel, belirlenmiş bağlamının dışına çıkarak sivil toplum kuruluşları aracılığıyla faaliyet sahasını ve hedef kitlesini genişletmiştir (Pantoja, 2018).

Günümüzde uygulayıcısı ve hedef kitlesi insan olan kamu diplomasi faaliyetleri makine merkezli bir sisteme dönüşmüştür. Makine merkezli kamu diplomasinin temeli yapay zekâ teknolojisine dayanmaktadır. Diğer bütün alanlardaki uygulamalarında olduğu gibi kamu diplomasisi alanında da yapay zekânın kullanımı etki ve etik tartışmasını içermektedir. Kamu diplomasisi alanında yürütülen akademik çalışmalara yönelik literatür analizlerinde (Sevin, Metzger ve Hayda, 2019; Manor, 2017; USC Center on Public Diplomacy at the Annenberg School ve Clingendael Netherland Institute of International Relations, 2014; Almuftah, Weerak-

${ }^{1}$ Gilboa, 2001; Leorand, M., Stead, C ve Smewing, C. 2002; Mellisen, 2005; Fitzparticrk, 2008; Zaharna, 2007; Norrman, 2013) 
kody ve Sivarajah, 2016, Makine ve yapay zekânın kamu diplomasisi eylemlerinde ortaya çıkaracağı sonuçlara yönelik tartışmaların yeterince ele alınmadığı görülmektedir. Bu çalışmada kamu diplomasisi faaliyetlerinde yapay zekâ kullanımı, etik ve etki sorunsalı çerçevesinde analiz edilmektedir. İcracısı ve muhatabı insan olan klasik kamu diplomasisinden, makine merkezli kamu diplomasisine geçişte insan faktörünün hem icra hem de muhatap bağlamında belirsizleşmesinin ortaya çıkardığı etkiler kontrol, denetim, güvenlik, etki ve etik çerçeve esasında tartışılmıştır. Araştırmanın temel çerçevesi şu varsayımlar üzerine dayandırılmıştır: Makine merkezli kamu diplomasisinde insan, eylemin icracısı ve muhatabı olmaktan çıkmıştır. Bu durum kamu diplomasisi eylemlerinin etkisini sorgulamayı gerekli kılmaktadır. Kamu diplomasisi eylemlerinde yapay zekâ kullanımı, "Eylemin sorumluluğu kimdedir?" şeklindeki etik bir soruyu ve tartışmayı beraberinde getirmektedir.

\section{Geleneksel Kamu Diplomasisi: İnsani İletişim ve Etkileşim}

Yumuşak gücün kilit araçlarından biri olan kamu diplomasisi uygulama bağlamında çağdaş tartışmalardan önce bir eylem pratiği olarak diplomatik sahada teşekkül etmiştir (Mellisan, 2005; Helmers, 2016). Çeşitli eylem ve faaliyetlerle ülke çıkarlarının ve imajının başka ülke ve kamuoyları nezdinde yükseltilmesine yönelik faaliyetler Antik Yunan'dan günümüze farklı yöntem ve araçlarla uygulanagelmiştir. Erken dönem diplomasi tarihinde diplomatların yabancı ülke kamuoylarıyla ve elitleriyle iletişime geçtikleri, ülke kamuoylarını etkilemek için birtakım edebi ve sanatsal faaliyetler yürüttükleri görülmektedir. Erken dönem diplomasi tarihinde "yabancı ülke kamuoyuyla etkileşim kurmanın geleneksel yolu broşürlerdi. Özellikle savaş zamanında, çok dilli broşür yayınlama kampanyaları son derece yaygındı" (Helmers, 2016, s. 406).

Soğuk savaşın ilk yıllarında kamu diplomasisi genellikle psikolojik savaşla bağdaştrrılan bir terim olarak görülmektedir (Lord, 1998, s. 52). Kamu diplomasisi disiplinlerarası bir alan olarak çeşitli bilimsel disiplinlerle ve farklı kurum ve yapılarla ilişkilidir. Kamu diplomasisi enformasyon ve bilgilendirme, kültür, ticaret, eğitim, değişim, sanat ve bilim gibi alanlarla yakından ilişkilidir.

Klasik kamu diplomasi faaliyetlerinin temeli, insani iletişim ve etkileşim gerektiren eylem ve kurumlara dayanmaktadır. Klasik kamu diplomasisi eylemleri olan kültür diplomasisi, uluslararası yayıncılık, insani yardım ve sivil toplum kuruluşları üzerinden yürütülen kamu diplomasisi eylemleri temel olarak insanlar arası ilişki ve iletişim gerektiren eylemlerdir. Sevin, Metzger ve Hayda (2019, s. 4824), kamu diplomasi literatürüne yönelik gerçekleştirdikleri meta analizinde 1965 ile 2019 
yılları arasında hakemli akademik dergilerde yayınlanmış çalışmaların başlık ve özetlerinde en çok kullanılan on kelime arasında kültür, uluslararası ilişkiler, politika, ilişki, dünya ve medya kelimelerinin geçtiğini tespit etmiştirler. Araşttrmada bulunan ilgili kelimeler insani eylem ve iletişimle doğrudan ilişkilidir. Bu kelimelerin içerdiği eylemlerde eylemin yürütücüsü ve hedef kitlesi insandır.

Yüz yüze ve doğrudan iletişim kamu diplomasisi eylemlerinin bütününde görülmekle birlikte en yoğun şekilde uluslararası eğitim ve değişim programları ile kültür diplomasisi alanlarında görülmektedir. Özellikle de Avrupa kamu diplomasisi faaliyetlerinin temeli insani ilişkilere ve kamu diplomasisi faaliyetlerinin kültür ve iletişim faaliyetleri üzerinden yürütülmesine dayanmaktadır. Fransa, (Fransız Kültür Merkezi) Almanya (Goethe Enstitüsü) ve İngiltere (British Council) gibi ülkeler güçlü kültür diplomasi kurumlarına sahiptir. Avrupa'daki güçlü kültür diplomasi kurumlarının yanında Çin'in 2007 yılında kurduğu ve ağ yaklaşımına göre yapılandırdığı Konfüçyüs Enstitüsü kültür ve dil diplomasisinin yeni ve güçlü bir örneğini sergilemektedir (Zaharna, 2012; Flew, T., Hartig, F, 2014).

Klasik kültür diplomasisi faaliyetleri farklı ülkelere dil ve kültür merkezleri açma, bu ülkelerde birtakım eğitim, kültür ve sanat faaliyetlerinin yürütülmesini kapsamaktadır (Norrman, 2013; Institute for Cultural Diplomacy, tarihsiz).

Sanatsal sergi, müzik festivali, dil öğretimi, sanat eğitimi gibi faaliyetler yüz yüze iletişim yoluyla gerçekleşmektedir. Benzer bir yapıyı insani yardım faaliyetlerinde ve bir dereceye kadar geleneksel kitle iletişim araçları üzerinden yürütülen uluslararası yayıncılıkta görmek mümkündür. Klasik kamu diplomasisi faaliyetlerinde doğrudan iletişim ve insani etkileşim gerçekleştirilen faaliyetlerin doğasının bir sonucudur. Sergiler, müzik festivalleri, insani yardım faaliyetleri, değişim ve liderlik programları iletişim ve etkileşimi esas almakta ve hedef kitle ile doğrudan temasa dayanmaktadır.

\section{Yeni Kamu Diplomasisi: Teknolojinin Kolaylaştırıcı Rolü}

Yeni medya ve internetin her alanda artan etkisi ve kullanımı kamu diplomasisini de etkilemiştir. Bu etki kamu diplomasi literatüründe Kamu diplomasisi 2.0 şeklinde adlandırılmaktadır. Kamu Diplomasi 2.0 tanımlaması kamu diplomasisi eylemlerinde internet ve bilişim teknolojisinin etkisine vurgu yapmaktadır (Manor, 2018). Yeni kamu diplomasisi tanımlaması üç temel üzerinden şekillenmekte ve kamu diplomasi faaliyetlerinde aktör, eylem ve söylemlerin dönüşümüne vurgu yapmaktadır. Yeni kamu diplomasinin dayandığı üç temel noktayı şu şekilde sıralamak mümkündür: 1) kamu diplomasi faaliyetlerinde internet ve teknoloji kullanımının artan etkisine vurgu, 2) kamu diplomasisi faaliyetlerinin tek yönlü 
iletişim ve eylem süreçlerinden çift yönlü iletişim ve etkileşime olanak tanıyan alana kayması, 3) kamu diplomasisi faaliyetlerinde aktörlerin çeşitlenerek sivil toplum örgütlerinin de birer kamu diplomasi uygulayıcısı olması ( Mellisen, 2005; Hocking, 2005; Zaharna, 2007).

Kamu diplomasisi faaliyetleri iyi yetişmiş insan kaynağına, donanımlı ve organize yapılara ihtiyaç duymaktadır. Bu durum, kamu diplomasisi faaliyetlerini ekonomik bağlamda pahalı birer araca dönüştürmektedir. Ekonomik avantajlar, daha fazla etki ve teknoloji kullanımında yoğunluk ülkeleri kamu diplomasi faaliyetlerinde dijital diplomasiye yöneltmiştir. Cull (2009, s.14), eski ve yeni kamu diplomasisinin temel özelliklerini belirleyen taksonomisinde yeni kamu diplomasinin, eski kamu diplomasiden farklı olarak kısa dalya radyo ve basılı yayınlardan ziyade uydu, internet ve gerçek zamanlı mobil telefon teknolojisine dayandığını vurgulamaktadır.

11 Eylül 2001 tarihinde Amerika Birleşik Devletleri'nde Dünya Ticaret Merkezine gerçekleştirilen saldırıyla birlikte kamuoyu algısının ve ülke imajlarının dönüşümü önem kazanmıştır. Bu süreçte Amerikan kamu diplomasisi, "Dünya bizden neden nefret ediyor?" sorusu ve sorunsalı üzerinden şekillenmiştir (Günek, 2018). Bu soru yabancı kamuoylarını dinleme ve kamu diplomasisi faaliyetlerini bu sorunsal üzerinden yapılandırmaya yönelik birtakım eylemleri beraberinde getirmiştir. Kısaca stratejik iletişim olarak adlandırılan sonuç odaklı birtakım eylemler dizisi şeklinde kamu diplomasisi faaliyetleri şekillenmiştir. Bu dönemde kamu diplomasisinde çeşitli tanımlar ve teorik yaklaşımlar ortaya çıkmıştır. Stratejik kamu diplomasisi, diyalog ve ağ modeli gibi yaklaşımlar bir taraftan yeni iletişim teknolojilerini dikkate alırken diğer yandan da iletişim ve kamu diplomasisindeki en temel sorunlardan olan dinleme ve muhatapla daha fazla etkileşim sorununa değinmektedir ( Mellisen, 2005; Hocking, 2005; Zaharna, 2007; Hocking, 2009). Bu yaklaşımlardaki temel amaç, daha fazla etki anlayışı üzerine odaklanmaktadır. Bu teorik yaklaşımlar ABD Kamu Diplomasisi Genel Sekreteri tarafindan gerçekleştirilen Karen Hughes dinleme turu ${ }^{2}$ gibi çeşitli kamu diplomasisi faaliyetlerinde pratik olarak uygulanmaya çalışılmıştır (Jones, 2005; Wallin, 2012). Yabancı uluslarla iletişim ve etkileşiminin güçlendirilmesi amacıyla çeşitli sanal ağlar oluşturulmuştur. Yeni kamu diplomasinin öngördüğü temel esaslar dinleme ve kendini

\footnotetext{
${ }^{2}$ ABD Kamu Diplomasi Genel Sekreteri Karen Huges 2005 yılında Amerika'nın Müslüman dünyası nezdindeki imajını kamuoyu nezdinde düzeltmek ve ilgili ülkelerle fikir alışverişi yapmak amacıyla Türkiye, Suudi Arabistan ve Mısır’ kapsayan bir dizi ziyaret gerçekleştirmiştir. Karen Huges Dinleme Turu olarak adlandırılan bu ziyaretlerin temel amacı muhatapları dinleyerek sorunlara çözüm üretmektir (BBC News, 27 Eylül 2005).
} 
anlatma üzerine kurgulanmıştır (Cull, 2009; Fitzpatrick, 2011). Dinleme ve kendini anlatma üzerine kurgulandığı için daha geniş hedef kitleye etkili bir şekilde ulaşmak için internet ve teknoloji kullanımına artan oranda vurgu yapılmıştır. Faaliyetlerde teknolojinin kullanımı hedef kitleye ulaşım ve etki etme açısından istenilen sonuçları doğurmamıştır (Fitzpatrick, 2008; Wallin, 2012; Wharton, 2017). Kamu diplomasi faaliyetlerinde teknoloji kullanımı ve etkileşim biçiminin yeni kamu diplomasi faaliyetlerinin temelini teşkil eden dinleme, eşit ve açık iletişim gibi ilkelerin uygulanması açısından etkili sonuçlar doğurmadığını söyleyebiliriz.

\section{Makine Merkezli Kamu Diplomasisi: Insani Etkinin Kaybı}

Akademik bağlamda disiplinlerarası bir alana tekabül eden kamu diplomasisi uygulama düzleminde ise oldukça dinamik bir alandır. Küresel politik süreçler, ülkelerin hedef ve söylemleri, teknoloji ve uluslararası sistemdeki kurumsal dönüşümler kamu diplomasisi alanını doğrudan etkilemektedir. Bütün bu gelişmeler ışığında son dönem kamu diplomasisinin temel odak noktasını bilişim ve internet teknolojisindeki gelişmeler önemli oranda etkilemekte ve başat unsur olmaya başlamaktadır.

Günümüzde kamu diplomasisi, dijital diplomasi ile çok farklı boyutlara gelmiştir. Klaus Schwab’ın “Dördüncü Endüstriyel Devrim” olarak adlandırdığı teknolojinin fiziksel, dijital ve biyolojik alandaki teknolojik füzyonuna dâhil olmuştur. Bu yıkıcı teknolojiler arasında nesnelerin interneti, sanal ve artırılmış gerçeklik, yapay zekâ, robotik, otonom araçlar, 3-D yazıcı, nanoteknoloji, biyoteknoloji, enerji depolamak ve kuantum hesaplama girmektedir. (Schwab'tan aktaran, Chapman, 2019 , s. 11). Kamu diplomasi Schwab’ın “dördüncü endüstriyel devrim” olarak nitelediği sürece bilişimsel propaganda ve Makina Merkezli Illetişim (MADCOM-Machine Driven Communication) ile dâhil olmuştur. Günümüzde dijital teknoloji marifetiyle milyarlarca verinin üretimi, analizi, sınıflandırılması, dağıtımı zaman kısıtlaması olmadan yürütülmektedir. Dijital diplomasi, veri diplomasisi, makine merkezli diplomasi, bilişimsel diplomasi gibi farklı şekillerde adlandırılan bu süreç aynı zamanda kamu diplomasisi araştırmaları için disiplinler arası bir araştırma ve tartışma sahası oluşturmuştur.

Uygulama bağlamında etkili kamu diplomasisi faaliyeti yürüten ülkeler yeni sürece uyum sağlamak için kamu diplomasi kurumlarını, mevzuatlarını ve teşkilatlarını yeniden düzenleme ihtiyacı hissetmişlerdir. Kamu diplomasi kurumları dijital diplomasinin olanaklarını daha aktif kullanmak amacıyla esnek ve proaktif anla-

\footnotetext{
${ }^{2}$ Makine öğrenimi kavramı, algoritmaların öğrenebilirliğini ve bu doğrultuda hareket edebilirliğini ifade etmektedir.
} 
yışa göre şekillenmiştir. Amerika Birleşik Devletleri , Ingiltere ve Avrupa Birliği Kamu diplomasisi politikaları bilgi ve iletişim teknolojilerinin daha aktif ve etkili kullanımı gerçekliği üzerine yeniden değerlendirilmiştir (Gouvieia ve Plumridge, 2005; Gregory, 2011; McClory, 2015 ).

Kamu diplomasisi faaliyetlerinde bilgi ve iletişim teknolojilerinin kullanımını ve makineleşmeyi içeren süreç kamu diplomasisi literatüründe genellikle dijital diplomasi kavramıyla açıklanmıştır. (Manor, 2016; Manor; 20017; Bjola, 2019). Dijital diplomasi faaliyetlerinin erken dönem çalışmalarını Çin Halk Cumhuriyeti aktif bir şekilde yürütmektedir. 1999 yılında diplomasi bürokrasisinde değişikliğe giden Çin, Dışişleri Bakanlığı Enformasyon Bölümü bünyesinde internet bürosunu kurmuştur. 2010 yılının başlarında ise Çin Enformasyon Birimi Kamu Diplomasisi Ofisi olarak Çin siber diplomasisini organize etmek üzere daha geniş sorumluluklar çerçevesinde yeniden yapılandırılmıştır. (Wang, tarihsiz, 146).

Yapay zekânın 1950'lerden günümüze geçirdiği serüveni ele alan Bjola (2019), yapay zekânın konsolosluk hizmetleri, kriz yönetimi, kamu diplomasisi ve uluslararası müzakereler gibi diplomatik çıkar alanlarında güvenilir yardım sağlaması durumunda diplomaside kullanımının artacağını iddia etmektedir. ABD, Kanada, Rusya ve Çin'in yapay zekânın diplomasi ve kamu diplomasisinde kullanımına yönelik girişimleri yapay zekâyı etkili bir araç olarak gördüklerini işaret etmektedir. Dış politikada yapay zekâ kullanımını öngören Çin, 2030 yılana kadar bu alanda dünya lideri olmayı hedefleyen "Yeni Jenerasyon Planını" benimsemiştir. Çin uluslararası politik süreçlerde yapay zekâyı karar alma süreçlerine yardımcı bir unsur olarak kullanmaktadır. Çin Bilimler Akademisi Dışişleri Bakanlığında uygulanan ve kullanılan makine temelli algoritmalar geliştirmiştir (Amaresh, 2020). Başkan Xi Jinping yönetimindeki Çin, aktif bir siber uzay politikası benimsemiştir. Bu siber uzay politikasının temel amacı, “Internetin ve bilgi akışının iç istikrara ve rejim meşruiyetine karşı oluşturabileceği tehdidi sınırlamak; Pekin'in siyasi, askeri ve ekonomik etkisini genişletmek için siber uzayı şekillendirmektir" (Segal, 2017, s. 2).

Çin gibi Rusya, Kanada ve ABD de yapay zekânın dış politikadaki etkisine önem vermektedir. Rusya yapay zekânın yeni dünya düzeni üzerinde belirleyici rolü olduğuna vurgu yapmaktadır. Kanada dış politikada yapay zekâ kullanımını çeşitli yatırım ve faaliyetlerle kurumsallaştırmıştır. (Amaresh, 2020). ABD Enformasyon Teknolojileri Stratejik Planlama Ofisinin 2017-2019 raporuna göre ABD diplomatları politika değişikliklerini yapmak, şeffaflık ve farkındalığı artırmak için güçlü yapay zekâ teknolojileri kullanmaktadır. Center for New America raporuna göre uluslararası güvenlik ve yönetimle ilgili alanlarda yapay zekânın önemli bir potansiyeli bulunmaktadır. 
Bunlar:

-Uluslarası iletişimde dil engelini en aza indirmek,

-Seçimleri izlemek,

-Uluslararası insani yardım organizasyonlarına yardım etmek,

-Diplomatik misyonların güvenliğini güçlendirmek

-Yabancı haklar ve hükümetler arasındaki iletişim boşluklarını kapatmak" Amaresh (2020).

Yapay zekânın kamu diplomasisinde kullanımı çeşitli açılardan fayda ve riskler içermektedir. Yoğun teknoloji kullanımı ile yürütülen ve merkezinde yapay zekânın yer aldığı yeni tarz kamu diplomasisini şekillendirecek temel etmen, bu alandaki teknolojik ilerleme ve yenilikler gibi etki ve etik tartışması olacaktır. Kamu diplomasisini bu etik çerçeveye yerleştirmeden alanda etkili ve anlamlı faaliyetlerin yürütülmesi zorlaşmaktadır.

\section{Makine Merkezli Kamu Diplomasisinde Etki ve Etik Tartışması}

Kamu diplomasisi literatürü, genellikle dijital diplomasi, bilişsel diplomasi ya da makine merkezli kamu diplomasisi olarak tanımlanan ve temelde kamu diplomasi faaliyetlerinin internet ve teknoloji marifetiyle yürütülmesini esas alan yaklaşımlara yönelik pozitif bir tutum sergilemektedir. ${ }^{3}$ Bu yeni tür kamu diplomasisinin ortaya çıkardığı sonuçların insani ve etik boyutu ise kısıtlı bir tartışmanın konusudur. Bilişimsel kamu diplomasi faaliyetlerinin temel tartışma noktalarının üç bağlam üzerinden şekillendiği görülmektedir. Bunlardan birincisi, bilişsel faaliyetlerin teknik ve entelektüel sahipliği ve kontrolü, ikincisi ise hukuki ve teknik denetimi ile genellikle yanlış kullanımını içeren güvenlik sorunudur. Makineler üzerinden yürütülen faaliyetlerin ortaya çıkardığı teknolojik determinizm, yine internetin yapısal özelliklerinden kaynaklanan ve etik tartışmayı da içeren bilginin güvenirliği ve hakikat sorunu ise diğer bir tartş̧ma boyutudur.

Bir insanı bilişsel ve fikirsel bağlamda algoritmalar üzerinden yürüyen yapay zekâ teknolojisiyle tatmin etmek mümkün müdür? Yada otomatik yorum metinleriyle bir ülkenin dış politikasını savunmak ne kadar gerçekçidir? İlgili sorular esas itibariyle kamu diplomasi faaliyetlerinin merkezinde yer alan etki tartş̧malarına, eylemde kullanılan araçlara, kaynak ve hedef arasındaki ilişkiye gönderme yapmaktadır. Klasik kamu diplomasisi, yeni kamu diplomasi ve stratejik kamu diplo-

\footnotetext{
${ }^{3}$ (Sevin, Metzger ve Hayda, 2009; Manor, 2017; USC Center on Public Diplomacy at the Annenberg School ve Clingendael Netherland Institute of International Relations, 2014; Almuftah, Weerakkody ve Sivarajah, 2016)
} 
masisi yaklaşımının hatta propaganda temelli iletişim ve enformasyonun temelinde "etki" meselesi yer almaktadır ve bütün yaklaşımların temel amacı hedef kitleyi ikna etmektir (Gilboa, 2001; Leorand, M., Stead, C ve Smewing, C. 2002; Gregory, 2005; Mellisen, 2005; Zaharna, 2007; Norrman, 2013).

Kamu diplomasisinde yapay zekâ kullanımı dispotik bir bağlamla insan karşısına makineyi konumlandıran bir sürece işaret etmektedir. Chessen'e (2017b) göre bu süreç gelecekte "Insanlarla konuşan makineler, makinelerle konuşan insanlar" ortaya çıkaracaktır. Bu durum insani iletişimi kısıtlamakta ve makineleri iletişim sürecinin başat aktörü yapmaktadır. Bu bağlamda tartş̧ılan konu ise yapay zekâ üzerinde insan kontrolünün ne derece mümkün olduğudur. Grottola (2018)'e göre bu bir yanılsama olabilir. Çünkü yapay zekâ algoritması mevcut üretilmiş verinin taklidi ve işlenmesi üzerine kurgulanmıştır. Bu da yapay zekâ kontrolünü güçleştiren bir unsurdur. Chessen'e göre (2017b, s. 39), "Yapay zekâ öğrenen bir makine olarak insan duygularını insanın yapabileceğinden daha iyi algılayabilecektir. Hangi mesajların en etkili olduğunu belirlemek için özelliklerinize sahip kişilerle A-B testleri çalıştıracak ve ardından bu mesajları benzer popülasyonlara dağıtacaktır." Yapay zekânın söz konusu yapısal özellikleri kamu diplomasisi eylemlerinde yapay zekâ kullanımını kontrol, denetim, güvenlik, etki ve etik bağlam açısından tartışmayı zorunlu kılmaktadır.

\subsection{Kontrol, Denetim ve Güvenlik İkilemi}

Yapay zekânın gelecek yıllarda erişeceği imkân ve kabiliyetler düşünüldüğünde insani yaratıcılık ve yetenek gerektiren birçok konuda insanoğlunu aşacak duruma geleceği öngörülmektedir. Önümüzdeki on yıllar boyunca yapay zekânın 2026 yılında iyi bir lise makalesi yazması, 2027 yılında tır sürmesi, 2049 yılında en çok satan popüler romanı yazması, 2053 yılında bir cerrah gibi ameliyat yapması ve önümüzdeki 120 yıllık süreçte insanoğlunun yapabildiği bütün işleri yapabilecek boyutlara ulaşması mümkün gözükmektedir (Grace ve Ark'tan aktaran Bjola, 2019, s. 3). Çok hızlı bir şekilde ilerleyen ve kabiliyet geliştiren yapay zekânın kontrolü fütüristtik ve distopik göndermelerin dışında hukuki ve entelektüel hakların önemli bir konusu olmaya başlamıştır. Özellikle bilgi üretimi ve dağıtımını içeren enformasyon süreçlerinde yapay zekâ kullanımı önemli sorunlar içermektedir. Makine merkezli propagandanın insani iletişim ve etkileşimle dengelenmesi olası senaryolar içinde mümkün gözükmemektedir. Chessen'e göre (2017b, s. 40), Sosyal medyanın büyük bir bölümüne fikir ve tartışmaya dâhil olabilen yapay zekâ algoritmasına sahip makineler sahip olacaktır. Makineler, kullanıcıları ikna etmeye, satmaya, aldatmaya, gözdağı vermeye, manipüle etmeye ve program- 
landıkları her türlü yanıt için kandırmaya çalışacaklar. Bilişimsel diplomasinin en temel unsuru olmaya başlayan yapay zekâ temelli gelişimler açısından en temel meselelerden biri yapay zekâdaki ilerlemelerin hızının uluslararası mevzuat kapasitesini geride bırakması durumunda, birçok ülkenin henüz onaylamadıkları ve hatta belki de anlayamadıkları teknolojik süreçlerin etkileri ile baş etmek durumunda kalacak olmalarıdır (Ünver, 2017, s. 10).

Yapay zekânın "kontrolünün” bir problem olarak karşımıza çıkması gibi "denetimi" de sorundur. Yapay zekânın kontrolü ve denetimine ilişkin yasal altyapı henüz belirginleşmemiştir. Diğer bütün uygulama alanlarında olduğu gibi yapay zekânın kamu diplomasisi uygulamalarında da temel tartışma konusu yapay zekâ süreçleri üzerinde insan kontrolü üzerine odaklanmaktadır (Diplo, 2020). Yapay zekânın iş gücüne, yönetime ve topluma nasıl katılması gerektiğiyle ilgili tartş̧malar sürmektedir. Günümüzde vatandaş robotlar kavramının dahi ortaya çıktığı bir süreci yaşıyoruz. (Puaschunder, 2019).

Yapay zekâ üzerine yürütülen tartışmaların tümü küresel bir internet tabanına dayanmaktadır. Ancak çeşitli bağlamlarda internetin artık gelecekte küresel olmaktan çıkabileceğine ilişkin görüşler mevcuttur. 2025 yılında hâlâ küresel bir internetten söz edebilecek miyiz sorusunu yönelten Manor'a göre (2017), siber saldırılardan ve ülkelerin çeşitli nedenlerden dolayı kendi güvenlik ve ulusal altyapısını oluşturması ve internet üzerinden ulusal kontrolü sağlama gibi amaçlardan dolayı küresel bir internet ağından söz etmek zorlaşacaktır.

Birleşmiş Milletler İnsan Hakları Evrensel Bildirgesi'nin 19. maddesi ve Avrupa Insan Hakları Sözleşmesi'nin 10. maddesinde ele alındığı şekliyle genelde bilgiye özelde ise internete erişim bir insan hakkı olarak görülmektedir (ombudsman. gov.tr, tarihsiz; yargıtay.gov.tr, tarihsiz). Bilgiye ve internete erişimin çeşitli yollarla engellenmesi demokratik insan hakları engeli oluşturduğu gibi ileri düzey teknolojiler çeşitli örneklerde elektronik bir gözetleme ve denetim sistemine de dönüşebilmektedir. Örneğin Çin, nüfusunun davranışını izlemek için tasarlanmış bir sosyal sıralama sistemi uygulamaktadır. Sistem, özel sektörle ortaklıklar yoluyla elde edilen verilere dayanarak vatandaşlarını davranışlarına göre puanlandırmaktadır. Çin'in yaklaşımı Güney Afrika, Tanzanya ve Etiyopya'ya yayılarak Çin ile sınırlı olmayan ulusötesi bir eğilim ortaya çıkarmaktadır (Grottola, 2018). Siber çağda internetin ve dijital teknolojinin nasıl yönetileceğine yönelik soru özünde politik bir sorunsala işaret etmektedir. Buradaki temel soru, toplumun ve küresel kaynakların nasıl yönetileceğine yönelik sorundur (Riordan, 2019, s. 9). Güvenlik, kontrol ve daha kolay yönetim amaçlı olarak internetin küresel bir yapıdan ulusal ya da bölgesel bağlamlara indirileceğine yönelik tartışmalar günümüzde siber 
güvenlik konusunu hâlâ uluslarüstü bir sorun olmaktan çıkaramamıştır. Konunun çözümü de küresel bir iş birliğini gerektirmektedir (Chapman, 2019).

\subsection{Etki Tartışması}

Kamu diplomasisi eylemlerinin temel amacı hedef kitle üzerinde kaynağa yönelik olumlu bir etki oluşturmaktır. Eylemin hedef kitlenin düşünce ve tutumlarında ne tür değişiklikler oluşturduğu kamu diplomasisi faaliyet dönütleriyle elde edilmektedir. Kamu diplomasisi eylemlerinde etkinin ölçümü için hedef kitleye eylem öncesinde planlama ve eylem sonrasında ise etki ölçümü için odak grup araştırmaları, anket, yüz yüze görüşme, derinlemesine mülakat teknikleri, internet ağ analizi gibi çeşitli teknikler kullanılmaktadır. Kamu diplomasisi eylemlerinin somut çıktılarını görmek ve hedef kitle üzerindeki etkisini ölçmek zordur.

Dijital kamu diplomasisi eylemlerinde etki ölçümü dijital olanaklarla ve sayısallaştırılmış verilerle elde edilmektedir. Kamu diplomasi eylemenin planlayıcısı, yürütücüsü ve eylem sonucunda ortaya çıkan etkinin ölçeni aynı dijital araçlarla yürütülmekte ve planlanmaktadır. Makine tarafindan üretilen, kendi kendine öğrenen ve çoğalan içeriğin hâkim olduğu bir dünyada, iletişim kampanyaları bütünlük içinde yürütülmektedir (Chessen, 2017b, s. 43). Gelecekte yapay zekâ sohbet robotları, konuşma tarama araçları ve dinamik içerik oluşturma araçları, insanlarla iletişim kurarken insanların tepkilerini ve niyetlerini ölçebileceklerdir (Chessen, 2017, s. 44). Bu durum kamu diplomasisi eylemlerinin dönütlere bağlı olarak yeniden tasarlanması ve kullanıma sokulması açısından önemli imkânlar sunmaktadır. Eylem dönütlerini sayısallaştırmakta ve hedef kitlenin hangi düzeyde bilgilendirildiğini, ne tür geri dönüşler alındığına yönelik veriler sunabilmektedir.

Bilişsel propaganda yöntemiyle bir ülkenin politik tezlerini savunmak hedef kitleye ulaşmak açısından önemli avantajlar içermektedir. Ancak hedef kitle üzerindeki etkisi tartışmalıdır. ABD'de de 2010 yılında kurulan Terörizmle Stratejik Mücadele Illetişim Merkezinin (CSCC) dijital platformda hedef kitleye ulaşma ve hedef kitleyi etkileme başarısı sorgulanmaktadır (Wharton, 2017, s. 9). Benzer şekilde ABD’nin 11 Eylül sonrasında aşırıcılıkla mücadele amacıyla yürüttüğü "Shared Volues" (Ortak Değerler) kampanyası ve "Welcome to ISIS Land" kampanyası gerçek sorunları dile getirmemesi, kaynağa yönelik güven problemi oluşması, gerçek sorunlara değinmemesi nedeni ile istenilen başarıyı yakalayamamıştır (Wharton, 2017, s. 9). Dijital kamu diplomasi eylemleri daha fazla hedef kitleye daha az maliyetle ulaşma imkânı sunmasına karşın hedef kitle üzerinde kaynağın güvenirliliği, söylem ve hedef kitlenin gerçek sorunlarını ele 
almaması nedenleriyle başarısız olabilmektedir. Ancak hedef kitle ile empati geliştiren ve hedef kitlenin sorunlarına inebilen dijital kamu diplomasi eylemlerinin belli oranda başarı sağladığı görülmektedir. Örneğin DEAŞ terör örgütünden kaçanların hikâyesinin ele alındığı bir sosyal medya ve internet kampanyası olarak DEFACTOR kampanyası hedef kitle üzerinde etki oluşturmuştur (Wharton, 2017 , s. 10).

\subsection{Etik Tartişma}

Yapay zekâ etiğiyle ilgili tartşmaların temeli kendini geliştirebilen bir yapay zekânın hukuki ve ahlaki sorumluluğu noktasına odaklanmaktadır. Yapay zekâ ve süper yapay zekâların etik sorumluğunun bağlayıcılığı ve ortaya çıkardığı etki bütün boyutlarıyla tartışılmaktadır (Dilek, G. 2019). Yapay zekâya yönelik uygulamalı etik açısından yürütülen tartışma, kamu diplomasisi eylemleri özelinde de önemli bir tartı̧̧ma alanına tekabül etmektedir. "Eylemdeki etik sorumluluk kimdedir?" sorusu ve sorunsalı kamu diplomasi eylemleri için önemli bir tartışma konusu olmaktadır. Zira yapay zekâ tarafindan yürütülen bir kamu diplomasisi eyleminde kaynağın belirsizliği söz konusudur. Bu durum, kaynağa ve mesaja güven problemi oluşturabilir. Kamu diplomasisinde diyalog modeli (Fitzpatrick, 2011), ağ modeli (Zaharna, 2007), stratejik kamu diplomasisi (Flew, T ve Hartig, F, 2014; Hocking, 2005) gibi yeni kamu diplomasisi uygulamaları ve modelleri demokratik ilkelerle bağdaşan katılımcı, eşitlikçi ve şeffaf ilişki ve eylemlere dayanmaktadır. Makine merkezli kamu diplomasisi eylemleri ise yapay zekâ ve teknoloji kullanımından dolayı katılımcı, şeffaf ve eşitlikçi ilişkiyi ortadan kaldırmaktadır. Makine merkezli kamu diplomasisi:

-Teknolojik olarak kaynağın belirsiz olması,

-Teknolojiye ulaşma açısından eşitlikçi bir düzlemde yer almaması, ileri düzey teknoloji imkânlarını elinde bulunduran ülkelerin ve kurumların daha etkin kullanımına uygun olması, az gelişmiş ülkeler aleyhine bilgi açığı oluşturması açısından sorunlar içerdiğini söyleyebiliriz.

Kamu diplomasi eylemlerinde yoğun teknoloji kullanımı, hedef kitle belirleme, bilgi ve enformasyon sağlama ve bunları ilgili kitlelere karşı kullanmak makine merkezli yeni kamu diplomasinin en önemli araçlarındandır. Ancak bilgiyi elde etme, kullanma ve yayma açısından temel bir etik problem bulunmaktadır. Buradaki temel problem kamu diplomasisi eylemlerinde kullanılan yöntemlerin çoğunlukla yabancı ulusları kapsamasıdır. Örneğin ABD’de Kamu diplomasi ve propagandanın iç kamuoyuna yönelik olarak kullanılması kanun ile yasaklanmıştır (Wharton, 2017). 
Dijital kamu diplomasi enformasyon ve bilgilendirmeye dayanmaktadır. Bu eylemler potansiyel olarak dezenformasyona açıktır. Ayrıca dezenformasyonla savaş kamu diplomasisi eylemlerinin önemli amaçlarından biridir. Post Truht (hakikat ötesi) çağda doğru bilginin önemi artmıştır. Hakikat hâlâ geçerli, arzu edilen ve değerli bir olgudur (Wharton, 2017, s. 11). Ancak bu enformasyon ortamında doğru bilgiyi etkili bir yöntemle aktarmak güçleşmiştir. Bilgisayar temelli bilişimsel propaganda kamu diplomasisi eylemlerini teknolojik belirlenimciliğin önemli bir unsuru hâline getirmektedir. Bot ${ }^{4}$ hesaplar aracılığıyla yürütülen siyasal propaganda yöntemleri karmaşık bir yapıyla oluşturulmuştur. Bu yapılar yapay zekâ yöntemleri ile güçlenmekte ve teknik olarak tespit edilip önlenmesi de zorlaşmaktadır. Oxford Üniversitesi Internet Araştırmaları Merkezinden C.Woolley'e göre etik tartş̧maların önemli bir boyutu bilgisayar temelli propaganda ve bot hesaplardır. Son araştırmalar, çevrim içi sosyal ağlarda küresel siyasi bot hesapların yaygın bir şekilde kullanıldığını göstermektedir (C, Woolley, 2017, s. 13). Politikacılar, hükûmetler ve askeri kuruluşlar, siyasi iletişimi ve angajmanı manipüle etmek, tartışma zeminini ortadan kaldırmak ve siyasi meseleleri bulanıklaştırmak için özel bot yazılımlar kullanmaktadır (C, Wolley, 2017, s. 13). BotorNot ve Twitter Audit gibi araçlar both hesapları belirlemek için yeterli değildir ( C, Woolley, $2017,17)$. Bilişimsel propagandanın etkin bir şekilde kullanıldığı kamusal alanda dezenformasyonla mücadele teknik ve fikirsel açıdan zorlaşmaktadır. Bu düzlemde dezenformasyonu engellemek ve doğru bilgiyi yaymak imkânsıza yakındır. Soğuk savaş döneminde olduğu gibi dezenformasyonu hakikatle gidermek yerine karşı kampanyalar yürütülmesi önerilmektedir (Jakson, 2019, s. 42).

Yapay zekâ kullanımının artışı hedeflenen amaçların dışında birtakım politik ve sosyal etkiler ortaya çıkarmaktadır. Yapay zekâ uygulamaları elektronik gözetleme ve denetim sistemine dönüşebilmektedir. Bu gözetleme ve denetim sistemi Çin'in Vatandaş Puanlama Sistemi örneğinde olduğu gibi ulusal sınırları da aşarak uluslararası bir boyuta taşınmaktadır ( Grottola, 2018; Diplo, 2020).

Yapay zekânın çeşitli alanlardaki kullanımına yönelik olumsuz ve distopik görüşler mevcuttur. Ancak yapay zekâ kullanımı çeşitli açılardan olumlu etkiler ortaya çıkarabilmektedir. Bu alanlardan biri de insan hakları ihlallerinin takibi ve gözetimidir (Diplo, 2020). Özet olarak yapay zekânın kamu diplomasisi eylemlerinde kullanımının ortaya çıkaracağı sorunlar katılımcılık, açıklık, eylemlerin sorumluluğu ilkesi, bilgiye erişim ve teknolojinin kullanımı bağlamlarında gelecek dönemlerde de tartışılmaya devam edilecektir.

\footnotetext{
4“Bot, bir insandan ziyade bir algoritma tarafindan yürütülen sosyal ağ hesabıdır. Bir başka deyişle bot, insan müdahalesi olmaksızın içerik üretmek için tasarlanmıştı" ( Barojan, 2018).
} 


\section{Sonuç}

Makine merkezli bilişsel kamu diplomasi kurgulanırken insan ile makine arasındaki yapısal fark çoğu zaman göz ardı edilmektedir. Kamu diplomasi eylemlerinin içeriği ve yöntemi ne olursa olsun hedef kitlesi insandır. İnsanı ikna etmek üzerine kurgulanmıştır. Temel hedefi makineler üzerinden insanı ikna etmek olan bilişimsel kamu diplomasinin kullandığı araç ise makinelerdir. McLuhan'ın araç mesajdır yaklaşımı bağlamında bu durum derin bir teknolojik belirlenimcilik oluşturmakta ve yöntem yüzünden hedefini şaşırmaktadır (McLuhan, M ve Fiore, Q: 2012). Özellikle de internet ortamında kaynak açısından hedef kitlenin, hedef kitle açısından ise kaynağın, insan mı, yoksa makine mi olduğuna yönelik belirsizlik mevcuttur. Bu durum da kaynağın güvenirliği ve kaynağın açıklığı sorununu ortaya çıkarmaktadır.

Makine merkezli kamu diplomasisi faaliyetlerinin hukuki ve fikri altyapısı henüz netleşmemiştir. Bu alandaki mevzuat açıklığı yapay zekâ teknolojisinin hızlı bir şekilde gelişmesinden dolayı giderek artmaktadır. Yüksek teknoloji kullanımı bu teknolojiye sahip ve onu üreten ülkeler ile gelişmekte olan ülkeler açısından bilgi açığı oluşturmaktadır. Daha az gelişmiş ülkelerin yeterince etkili kamu diplomasisi eylemlerinde bulunmalarını engellemektedir. Yapay zekânın teknolojik yapısal özelliklerine bağlı olarak kontrol, denetim ve takip sorunsalı mevcuttur. Yapay zekânın bu özelliğine bağlı olarak yapay zekâ temelli kamu diplomasisi eylemlerinde "eylemin sorumluluğu" konusunun gelecek dönem tartışmalarında geniş bir şekilde yer alması öngörülmektedir.

Klasik ve yeni kamu diplomasisinden farklı olarak makine merkezli kamu diplomasisi insan faktörünü ötelemektedir. Ancak her alandaki yoğun teknoloji kullanımı ve kovid-19 pandemi sürecinin ortaya çıkardığı fiziksel kısıtlamalar kamu diplomasisini dijitalleşmeye yöneltmektedir. Diplomaside yapay zekâ temelli gelişimin etik ve etki bağlamı ise kamu diplomasi literatüründe tartışımamaktadır. Kamu diplomasisi eylemlerinde yapısal dönüşümü gerektiren bu durumun etik ve etki bağlamıyla tartışılması ve kamu diplomasi eylemleri için yeni etik kodlar üretilmesi önerilmektedir.

\section{Çıkar Çatışması Beyanı}

Makale yazarı herhangi bir çıkar çatışması olmadı̆̆ını beyan etmiştir. 


\section{Kaynakça}

Amaresh, P. (2020). Artificial Intelligence: A New driving horse in International Relations and Diplomacy, Diplomatist, Erişim adresi, https://diplomatist. com/2020/05/13/artificial-intelligence-a-new-driving-horse-in-international-relations-and-diplomacy/ Erişim tarihi: 01.02.2021.

Barojan, D. (2018). Both, Botnet ve Trolleri Anlamak, Newslab Turkey. Erişim adresi, https://www.newslabturkey.org/2018/12/06/bot-botnet-ve-trolleri-anlamak/ Erişim tarihi:03.03.2021.

BBC News. (2005). Envoy's Mid-east trip to revamp US image, 27 Eylül 2005. Erişim adresi, http://news.bbc.co.uk/2/hi/americas/4285102.stm Erişim tarihi: 15.11.2020.

Bjola, C. (2019). Diplomacy in the Age of Artificial Intelligence. Erişim adresi, http://www. realinstitutoelcano.org/wps/portal/rielcano_en/contenido?WCM_GLOBAL_CONTEXT=/elcano/elcano_in/zonas_in/ari98-2019-bjola-diplomacy-in-the-age-of-artificial-intelligence Erişim tarihi: 20.01.2021.

Chapman, J. (2019). Exploring the Threats and Opportunities of Cyber Diplomacy at PolicyWest, Public Diplomacy Magazine, Issue 2019, Winter, 11-14.

Chessen, M. (2017a). Understanding The Psychology Behind Computational Propaganda. Shawn Powers and Markos Kounalakis (ed.), Can Public Diplomacy Survive The Internet? Bots, Echochambers and Disinformation içinde (19-27.ss.) Erişim adresi: https://www.state.gov/wp-content/uploads/2019/05/2017-ACPD-Internet.pdf. Erişim tarihi: 23.04.2021.

Chessen, M. (2017b). Understanding The Challenges of Artificialintellingence and Computational Propanganda to Public Diplomacy. Shawn Powers and Markos Kounalakis (ed.), Public Diplomacy Survive The Internet? Bots, Echochambers and Disinformation içinde (39-49. ss.). Erişim adresi: https://www. state.gov/wp-content/uploads/2019/05/2017-ACPD-Internet.pdf Erişim tarihi: 23.04.2021

Cull, J, H. (2009). Public Diplomacy: Lessons Form The Past, Los Angeles: Figueroa Press

Dilek, G. Ö. (2019). Yapay Zekânın Etik Gerçekliği, AUSBD, 2(4): 47-59. e-ISSN: 2651-3064 Diplo (2020). Asia and Europe Public Diplomacy, Diplo.com, Erişim adresi: https://www. diplomacy.edu/asia-europe Erişim tarihi: 22.03.2021.

Fitzpatrick, K.R. (2011). U.S. Public Diplomacy in a Post-9/11 World: From Messaging to Mutuality. CPD Perspectives on Public Diplomacy, Paper 6. Los Angles: Figueroa Press

Fitzpatrick, K.R.( 2008). The Collapse of American Public Diplomacy, What Diplomatic Expert say About Rebuilding America's Image in The World, Erişim adresi, http:// www.publicdiplomacy.org/Fitzpatrick2008.pdf Erişim tarihi: 20.03.2021.

Flew, T., Hartig, F. (2014); Confucius institutes and the network communication approach to public diplomacy. The IAFOR Journal of Asian Studies, 1(1), 27-44.

Gilboa, E. (2001). Diplomacy in the media age: Three models of uses and effects. Diplomacy and Statecraft, 12 (2), $1-28$.

Gouveia, P.F ve Plumridge, H. (2005). European Infopolitik: Developing EU Public Diplomacy Strategy, London: The Foreign Policy Centre. Erişim adresi http:// www.kamudiplomasisi.org/pdf/kitaplar/EUpublicdiplomacystrategy.pdf Erişim tarihi: 14. 11. 2020 
Gregory, B. (2005). Public Diplomacy and Strategic Communication: Cultures, Firewalls, and Imported Norms, American Political Science Association Conference on International Communication and Conflict, erişim adresi , http://citeseerx.ist.psu.edu/viewdoc/download?doi=10.1.1.112.7338\&rep=rep1\&type=pdf Erişim tarihi: 18.04.2021.

Gregory, B. (2009). Mapping Smart Power in Multi-stakeholder Public Diplomacy / Strategic Communication, New Approaches to U.S. Global Outreach Conferansı, George Washington University, 5 Ekim 2009. Erişim adresi, https://pdaa. publicdiplomacy.org/? $p=52$ Erişim tarihi: 18.04 .2021

Gregory, B. (2011). American Public Diplomacy: Enduring Characteristics, Elusive Transformation, The Hague Journal of Diplomacy 6 (2011) 351-372.

Grottola, S. (2018). Artificial Intelligence And Diplomacy: A New Tool For Diplomats. Erişim adresi https://www.diplomacy.edu/blog/artificial-intelligence-and-diplomacy-new-tool-diplomats Erişim tarihi: 18.04.2021

Günek, A. (2018). Amerikan Kamu Diplomasisinin Üç Evresi: Propaganda, Geleneksel Kamu Diplomasi ve Stratejik Illetişim, The Journal of Social Science , 2 (3) 54-72 . DOI: $10.30520 /$ tjsosci.425898

Hamad Almuftah , H., Weerakkody, V., Sivarajah, U. (2016). E-Diplomacy: a Systematic Literature Review, ICEGOV2016, March 1-3, 2016, Montevideo, Uruguay. DOI: http://dx.doi.org/10.1145/12345.67890

Helmers, H. (2016) Public Diplomacy in Early Modern Europe, Media History, 22 (3-4) 401-420, DOI: 10.1080/13688804.2016.1174570

Hocking, B. (2005). Rethinking the New Public Diplomacy, Jan Melissen (ed.), The New Public Diplomacy, Soft Power in International Relations içinde (28-41) Palgrave Macmillan

Institute For Cultural Diplomacy (tarihsiz), Waht is Cultural Diplomacy? What is Soft Power?, erişim adresi, https://www.culturaldiplomacy.org/index. php?en_culturaldiplomacy\#: :text=\%22Cultural\%20Diplomacy\%20 may\%20best\%20be,beyond\%3B\%20Cultural\%20diplomacy\%20can\%20be Erişim tarihi: 25.05. 2021

Jackson, D. (2019). You Can't Solve Lying: Adapting to the Disinformation Age, Public Diplomacy Magazine, Issue 22, Winter 2019, 40-43

Jones, L. (2005). Karen Hughes' "Listening Tour" and Its Aftermath Selling America to the Muslim World, Washington Report on Middle East Affairs, December 2005, 24-26. Erişim adresi https://www.wrmea.org/005-december/two-views-karen-hughes-listening-tour-and-its-aftermath.html Erişim tarihi: 20.11.2020

Leorand, M., Stead, C ve Smewing, C. (2002). Public Diplomacy, The Foreign Policy Centre, London: Panton Hause

Lord, C. (1998). The Past and Future of Public Diplomacy, Orbis, Winter, 1998, 49-79.

Manor, I (2018). The Digitalization of Diplomacy: Toward Clarification of a Fractured Terminology, Working Paper No 2. Oxford Digital Diplomacy Research Group. Erişim adresi http://www.qeh.ox.ac.uk/sites/www.odid.ox.ac.uk/files/ DigDiploROxWP2.pdf Erişim tarihi: 15.02.2021. 
Manor, I. (2016). What is Digital Diplomacy, and how is it Practiced around the World? A brief introduction, The 2016 Annual Review of the Diplomatist Magazine. Erişim Adresi https://digdipblog.files.wordpress.com/2014/02/dig-dip-intro-diplomatist.pdf Erişim tarihi: 10.02.2021.

Manor, I. (2017). The Digitalization of Diplomacy: Toward Clarification of a Fractured Terminology. Working Paper. Exploring Digital Diplomacy, (Ağustos 2017). Erişim Adresi https://digdipblog.files.wordpress.com/2017/08/the-digitalization-of-diplomacy-working-paper-number-1.pdf Erişim tarihi: 15.02.2021.

McClory, J. (2015). The Soft Power 30 A Global Ranking of Power, Report Portland. Erişim adresi, https://portland-communications.com/pdf/The-Soft-Power_30.pdf Erişim tarihi: 20.02.2021.

McLuhan, M ve Fiore, Q (2012). Medya Mesajı, Medya Masajıdır, Illke Haydaroğlu(Çev), İstanbul: MediaCat

Mellisen, J. (2005). The New Public Diplomacy: Between Theory and Practice, Jean Mellisen (ed.), The New Public Diplomacy Soft Power in International Relations içinde (3-28. ss.) Palgrave Macmillan

Norrman, K.E. (2013). Definitions, Ideas, Visions and Challenges for Cultural Diplomacy, E International Relations. Erişim adresi http://www.e-ir.info/2013/01/03/definitions-ideas-visions-and-challenges-for-cultural-diplomacy/ Erişim tarihi: 13. 05. 2021

Ombudsman.gov.tr. (Tarihsiz). İnsan Hakları Evrensel Beyannamesi. Erişim adresi https:// www.ombudsman.gov.tr/document/mevzuat/688B1--Insan-Haklari-Evrensel-Beyannamesi.pdf

Pantoja, Y. M. (2018). How Do Non-State Actors Enhance PD?, USC Center on Public Diplomacy. Erişim adresi, https://uscpublicdiplomacy.org/blog/how-do-non-state-actors-enhance-pd Erişim tarihi: 20. 01.2021.

Puaschunder, J. M. (2019). Artificial Diplomacy: A Guide for Public Officials to Conduct Artificial Intelligence, Journal of Applied Research in the Digital Economy, (1) 39-54., http://dx.doi.org/10.2139/ssrn.3376302 Erişim tarihi: 20. 01. 2021.

Riordan, S. (2019). Cyber-diplomacy: Why Diplomats Need to Get Into Cyberspace, Public Diplomacy Magazine, Issue 2019, Winter. 09-11.

Segal, A. (2017). Chinese Cyber Diplomacy in a New Era of Uncertainty, A Hoover Institution Essay, Aegis Paper Series No. 170. Erişim adresi, https://www.hoover.org/sites/default/files/research/docs/segal_chinese_cyber_diplomacy.pdf Erişim tarihi: 16.04.2021.

Sevin, E., Metzgar, E.T, Hayden, C. (2019). The Scholarship of Public Diplomacy: Analysis of a Growing Field, Marine Corps University, USA International Journal of Communication, 13(2019), 4814-4837

USC Center on Public Diplomacy at the Annenberg School ve Clingendael Netherland Institute of International Relations (2014). The Digital Diplomacy Bibliogrpy. Erişim Adresi https://www.clingendael.org/sites/default/files/pdfs/Digital_ Diplomacy_Bibliography_2014_CLI-CPD.pdf Erişim tarihi: 18.02.2021.

Ünver, H.A (2017). Bilişimsel Diplomasi, Kadir Has Üniversitesi ve EDAM, Siber Politikalar ve Dijital Demokrasi Serisi, 2017/3 
Wallin, M (2012). The New Public Diplomacy Imperative, American Secrity Project. Erişim adresi https://www.americansecurityproject.org/public-diplomacy-and-strategic-communication/the-new-public-diplomacy-imperative/ Erişim tarihi: 20.04.2021.

Wang, W (Tarihsiz). Analysis on China's Cyber Diplomacy. Erişim adresi https://dspace. uni.lodz.pl/bitstream/handle/11089/12507/10-143_159-Wang.pdf?sequence=1\&isAllowed=y Erişim tarihi: 20.05.2021.

Wharton, B. (2017). Remarks on Public Diplomacy In Post Truth Society. Shawn Powers and Markos Kounalakis (ed.), Public Diplomacy Survive The Internet? Bots, Echochambers and Disinformation içinde (7-13. ss.)

Woolley, S.C. (2017). Computational Propaganda and Political Bots: An Overview. Shawn Powers and Markos Kounalakis (ed.), Public Diplomacy Survive The Internet? Bots, Echochambers and Disinformation içinde (13-19.ss.)

Yargıtay.gov.tr. (Tarihsiz). Avrupa İnsan Hakları Sözleşmesi. Erişim adresi, https://www. yargitay.gov.tr/documents/AlHM.pdf Erişim tarihi: 15.05. 2021.

Zaharna, R. S. (2007). The Soft Power Differential: Network Communication and Mass Communication In Public Diplomacy, The Hague Journal of Public Diplomacy, (3) 2, 213-228.

Zaharna, R. S. (2012). Analyzing China's Confucius Institutes as a Network Public Diplomacy Initiative. Paper prepared for International Studies Association, San Diego, CA, Nisan 1-4, 2012.

\section{Etichal and Impact Issues in Machine-Centered Public Diplomacy}

\section{Extended Abstract}

Public diplomacy activities, whose practitioner and target audience are human, have turned into a machine-centered system. The main focus of machine-centered public diplomacy is based on artificial intelligence technology. The use of artificial intelligence in public diplomacy activities, as in other fields, includes the discussion of impact and ethics. Literature studies show that studies in the field of public diplomacy mostly analyze concepts, institutions, actors and actions. (Sevin, Metzger, \& Hayda, (2009); Manor, (2017); USC Center on Public Diplomacy at the Annenberg School and Clingendael Netherland Institute of International Relations (2014); Almuftah, Weerakkody, and Sivarajah (2016)) effects of technology use on public diplomacy has not been sufficiently discussed.

The purpose of study; To contribute to the placement of machine-centered public diplomacy in a critical, ethical and humane context.

Method of the study: In this article, the use of artificial intelligence in public diplomacy activities is analyzed within the framework of ethical and impact problematic. Public diplomacy literature has been classified in the context of human 
communication. As a result of this classification, machine-centered public diplomacy, in which the human factor and influence has decreased, has been analyzed in the context of impact and ethics. The analysis was created in the context of "control", "audit", "security", "ethical framework" and "impact of action", which are at the center of artificial intelligence discussions

Results of the study: The gradual decrease in human impact in machine-centered public diplomacy makes the target audience and source uncertain. In this case, the reliability of the source, the responsibility of the source and the inability to determine the effect on the target audience raises the problem.

The use of artificial intelligence in public diplomacy actions creates technological determinism by eliminating human beings. There is a lack of legal and intellectual infrastructure in the use of artificial intelligence in machine-centered public diplomacy. Supervision, follow-up and security of actions will be at the center of future discussions. The increasing use of artificial intelligence in public diplomacy creates inequality of action between countries. Public diplomacy actions of underdeveloped countries are restricted and they cannot adapt to the new process. 